\title{
Insights of Models for Air Traffic Management System
}

\author{
Sabah Mohammed Fayadh, Saad Talib Hasson
}

\begin{abstract}
In many airports and air markets, congestion problems \& weather are becoming more and more severe. To keep Air Traffic Control (ATC) against the overload of Air Traffic Flow Management (ATFM) activity, attempts to anticipate and prevent the resulting overload and limit the delays. A delay in the arrival of the flight (so-called congestion) occurs when the traffic expects to surpass the arrival and departure capacity of the airport or the airsector capacity. There is a very extensive over general reasoning to be considered in this area. Generally speaking, most of the references found in the literature published a few years ago refer to the simplest versions, those that do not take airsector into account. This happens because the research was first done in the USA only, where traffic issues basicallylimited to the airports congestion. In the paper we present a comprehensive survey of the key optimization models of literature.
\end{abstract}

Keywords: Air Traffic Control, ATFM, Congestion.

\section{INTRODUCTION}

The continued growth of the aviation industry has placed a huge strain on the infrastructure of the aviation system. Congestion is constant and happens almost regularly as a result of even minor weather disruptions causing marginal power reductions [1, 2]. The European Air Transport Association (IATA) reports that air travelers are almost twice as large as 8.2 billion in 2037. Air transport has risen to 3 billion passenger kilometers (pkm) from the 70s of the last century to 2000. Fig.1.1. shows Passenger air transport grew from 3.5 trillion passenger kilometers worldwide to around 5.7 trillion passenger kilometers [2, 3] worldwide in the decade 2000-2010.

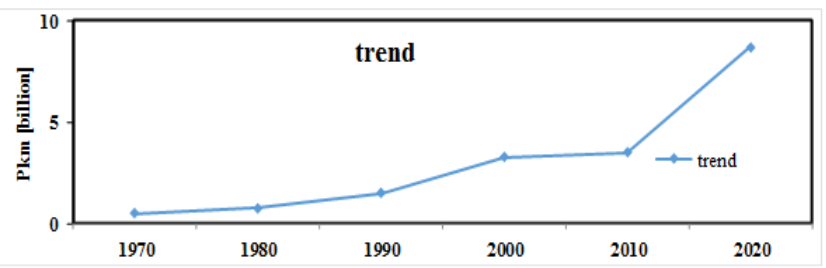

Fig. 1.1 Global predicted mobility trend of passenger air travel [3]

A global rise from 5.7 to 9 trillion passenger kilometers is projected for the next decade as well. Nevertheless, the airspaces have such a fixed size, and the number of airports that need to be constructed is not large enough to accommodate such increases in demand. Therefore, the Air Traffic Management (ATM) program allocates funds from airspace in a manner it may combine capability and demand. Meeting the capacity requirement and increasing arrival delays and cancellations are one of the most important challenges of Flight Path 2050.

Revised Manuscript Received on November 22, 2019.

* Correspondence Author

SABAH MOHAMMED FAYADH, College of Information Technology, University of Babylon, Iraq

SAAD TALIB HASSON, College of Information Technology, University of Babylon, Iraq
The need to develop the mathematical and computational model to estimate and forecast the congestion problem in the digital (tactical) plan and to avoid this congestion situation $[1,4]$. With such a long-term emphasis on their development of the general control system, ATM design will be introduced shortly..

The rapid development of air transport complicates the problem of air traffic congestion. There is an increasing inconsistency between restricted airspace assets and demand for traffic. As a result, an air transport network raises the fight against economic losses, delays and the risk of safety incidents [5]. Convective weather is an important factor that is detrimental to aviation safety. Data show that environmental conditions mainly cause accidents in combat, accounting for about $50 \%$ of all accidents in combat. In addition, environmental has become the main cause of delays in fighting. The US Federal Aviation Administration (FAA) announced in-depth research that about $65-75 \%$ of the combat delays over 15 minutes had a direct caused by weather conditions [6]. Due to the uncertainty of the weather forecast for terminal airspace, it is extremely difficult to estimate airport ability to devise effective traffic management strategies. The end time of the weather-related ground delay system was 95 minutes earlier than the original scheduled land delay schedule, for the 12 airways covered by FAA's National airspace system (NAS) Plan published in 2008 and 2009 [4, 5].For the next generation air transport systems, the FAA and the National Aeronautics and Space Administration are working to remove the negative impact of weather conditions on the NAS. We will also discuss the enhancement of integrated air traffic management by increasing the degree of automation and developing resources for decision support [6].Based on the weather radar echo and the 30-minute earlier short-term forecast, the FAA identified the weather-affected area of the air traffic management system to examine the effect of inclement weather conditions on route network analysis in the ATFM process. A network design was utilized to describe the entire environment, and the area influenced by extreme weather conditions was separated into 0-6 evaluations [7-9], spoke to by various colors. A study conducted at the Massachusetts Institute of Technology by the Lincoln Laboratory shows that third-or higher-grade weather conditions can cause aircraft bumpiness and ultimately reduce fighting performance [10]. If the amplitude of the echo reaches $41 \mathrm{dBZ}$, the war cannot proceed. Through applying this criteria, the restricted battle area can be clearly identified according to the route; however, due to the structural constraints in the terminal zone, the effect of the thunderstorm area on route coverage should be considered in order to improve and perfect the approach applicable to it.If the weather conditions influence the combat process, the maximum flow / minimum reduction theorem can be used to evaluate the potential of the sector concerned [7, 11]. 
The impact of convective weather conditions on the path of jet aircraft should be evaluated at the United States NAS.

This effect evaluation utilizes a convective climate avoidance (CWAM), a climate anticipation region, complete stream/least cuts sets and course blocking frequency[8, 12]. The tempest locale comprises of cumulonimbus mists and is a shut bend with expanding levels of precipitation within. A geometric strategy can be utilized for drawing the cloud structure of thunder storms dependent on the attributes of cumulonimbus. This methodology can likewise give reference to the vertex of the arched bend for rerouting adequately. In a way, the greatest stream/least slice hypothesis can be utilized to assess the impact of a rainstorm zone on the degrees of course inclusion in a terminal locale. As per factual hypothesis, the geographic locale of a tempest and the precipitation recurrence in a rainstorm zone can be consolidated to decide the traffic circumstance in a terminal zone while considering the terminal zone's precipitation force and topological structure.Most approaches to solutions are used to simplify the issue of air traffic control and find the most efficient route for all aircraft operating in the airspace network while maintaining a safe distance between them. The main focus is on too much realistic process modeling to help guides make the choices and estimation to achieve near-optimal real-time solutions. To achieve feasible and near-optimal individual flight paths, an integer packing problem is solved. Nevertheless, this model's computational efficiency was not sufficient to address issues encountered in practical, very large-scale instances [13].The mathematical model in this paper conquers that impediment and can handle issues of a scale equivalent to the two biggest ATFM frameworks right now being used.

A lot of airports and air markets, congestion problems are becoming more and more severe. To limit ATC from overloading a planning operation called Air Traffic Flow Management, it aims to predict and avoid the resulting overload and reduce the delays. A delay in the arrival of the flight (so-called congestion) occurs when the traffic expects to exceed the arrival and departure capacity of the airport or the airsector capacity. There are substantial additional costs caused by delays and are quantified [14] by an international organization: Total annual delay costs for European airlines due to congestion are reported to be EUR 5.73 billion / year in 1999 and USD 10 billion / year due to ATC activity resulting in deviations from acceptable aircraft flight profiles [15]. In September 2000, 20 percent of European Space flights were delayed due to ATC capacity constraints.

\subsection{Air traffic flow management (ATFM)}

The activity of the air terminal is controlled by the action of different air terminals by revolution of flying machine, for example a persistent trip of flying machine in one day between air terminals. The flow handling problem (FMP) occurs when, due to bad weather conditions or any other factors, the airport capacity of some airports decreases and leads to considerable delays of flight to and from airports. Additionally, ground holding delays can occur at origin airports to avoid airport delays due to shortages of airport capacity.

Apart of the ATFM is the method of allocating ground holds to aircraft. ATFM's task is to assign optimally capable of reducing foreseen negative impacts, e.g. extreme flight termination and flight delays, for all users during airport shortfalls $[15,16,20]$. The allocation of ground holds to departure aircraft was used as an operating technique to reduce flight delays and system costs due to delays. It performed a thorough investigation and description of FMP and ATFM, concluding that FMP is a concern with stochastic and dynamic characteristics and air traffic flow management strategies that should be studied using simulation techniques. In the early stage of ATFM design, air traffic flow management problems were once studied using deterministic models. Later, it was proposed that dynamic ground-holding assignments and stochastic models solve ATFM issues. It recently provided a systematic discussion of mathematical models and algorithms for research on air traffic flow management. In the latter, a detailed investigation was conducted to test different design assumptions as well as the problem-solving performance of the heuristics suggested for ATFM issues. More recently, the research focus on ATFM has moved within a multiple time frame to improving air traffic flow control in a multiple airport network. The performance of ATFM implementation was also evaluated using dynamic simulation methods in real-time as well as aircraft trajectory analyzes. Such FMP studies have established airport acceptance rate (AAR) modeling, i.e. short-term airport capability, as the key aspect of efficient ATFM efficiency optimization.AAR was modeled by deterministic power probes as well as stochastic ones in ATFM research because of the complexity of predicting an airport's AAR.

The problem of flow management is close to a general flow issue with originating airports supplying outflows of aircraft and destination airports receiving the flow. The allocation of aircraft ground holds therefore depends on the destination airport capacity. It was concluded that the importance of finishing proper models to simulate AAR is so essential to air traffic flow management efficiency that it is relatively unimportant when correct AAR forecasts can be provided, but how precise AAR forecasts can be made in advance. Because the AAR is affected by many variables such as airport configuration and environment, stochastic models have been found to be effective in capturing variations in airport capability over time. Nevertheless, the introduction of such models into the ATFM system has not yet been thoroughly investigated, although airport networks are likely to become bottlenecks in order to limit future growth in air transport (Flight International 2000). In addition to the modeling of AAR also considered the timing of providing reliable AAR estimates to be significant [15,17]. The inaccuracy of AAR forecasts accumulates over time and induces undue delay costs for device users when airborne aircraft are forced to postpone landing at an overcrowded airport. It outlined a way to improve ATFM implementation by improving the timing of AAR prediction notifications for future events. Sadly, the question of solving the methodology has not yet been investigated and further testing of the design implementation in an airport network is required. Another concern arises about the problem of consumer justice in the application of ATFM strategies. The allocation of ground delay and airborne delay to an aircraft depends on unit delay costs, estimated likelihood of delay and flight priorities.

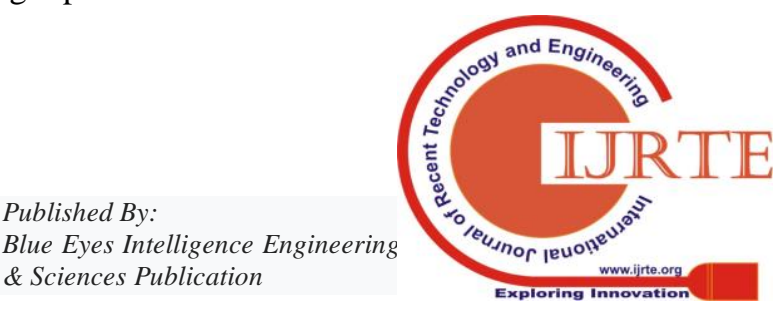


The literature showed that the rule of First-In-First-Out (FIFO) remains the fairest control strategy for all airspace users, but clearly not the ideal option for FMP resolution. However, proper inclusion of aircraft enroots flight time models would help improve ATFM's efficiency [18, 19]. Since many factors, such as airspace congestion and ATC controls, affect an aircraft's reroute flight time in the airspace, Modeling the aircraft's arrival time at the destination airport was usually done by following common assumptions, such as constant flight time models. However, the delay in departing the aircraft may be offset by flight buffer time, or simply by flying more quickly. Hence, the future research issue remains how ground-based delays can be allocated equally to balance ground and airborne delays among all users.

\subsection{ATM Functions}

Control the air traffic.

Operations and maintenance of airports.

To also maintain and develop the cargo terminals.

Provision of communication to guide the pilot.

\subsection{Challenges of Air Traffic Flow Management}

1. Not only will this technology challenge air traffic control. In the next seven years, Europe would have to prepare for $30 \%$ more flights, although there is already congestion at our main hub airports.

2. As well as minimal delay and optimum performance, traffic should be handled safely throughout the air and on the ground. The congestion phenomenon is recurrent or happens almost regularly as a result of poor weather conditions that cause drastic capacity reductions.

\subsection{Air Traffic Control (ATC)}

ATCs are carried out by air traffic controllers. It is a system that guides and supports aircraft in both airspace and on the ground in order to avoid collisions, adverse weather or other security problems. Air traffic controllers also ensure that in prohibited airspace the aircraft does not operate. We improve the flow of air traffic to achieve aircraft activity efficiency and controls that ensure secure separation between the aircraft at take-offs / landings as well as on the way.

Many researchers have been conducting research in these two directions in recent years; thus, on-line and off-line procedures. They introduced new control principles and developed some models and algorithms for optimization to improve air traffic management. ATC is divided into the following levels:

The first tier is related to long-term air space structure preparation, routes and ATC processes and generally to the general control system's long-term growth. The second level envisages the scheduling of flights within a short time period in accordance with expected traffic demand and other operational variables.[20].in most air navigation service providers, the ATM system is used concurrently by many individuals at various organizational positions. Typically these systems are built using the client-server architecture. Operational workstations are user devices, while data processing takes place on servers. The same information is available simultaneously on all workstations. The user interface of the functional workstation varies depending on the type of services provided by the role. For example, a radar controller workstation is different from both the tower controller workstation and the ASM workstation, the bulk of which was the show of traffic condition. The first level is known as ' strategic control, ' which is also a scheduling exercise with medium-long-term measures to organize traffic flows and/or to identify changes to single flight plans [21].Ultimately, strategic management is an operation of real-time control to fulfill short-term needs and/or to overcome emergency situations. Air traffic control (ATC) systems are sophisticated software systems. Their primary task is to help air traffic controllers maintain a safe and efficient flow of air traffic, but their scope of responsibilities is much broader: they also support airspace management (ASM) or air traffic flow and power management. This is why air traffic management (ATM) systems are open to them. The problem with the control of air traffic is a major problem, which:

1. The involvement within the multiple human operators (pilots, controllers, etc.), because they have the same autonomy throughout the decision-making process.

2. High number of variance or restrictions.

3. Complex relationships and various sub-systems.

4. There are also several control goals that contrast

5. Model limitations and complexity were used to forecast aircraft movement as well as traffic growth.

6. Rapid dynamics as well as real-time interference.

\section{RELATED WORK}

In the Aircraft Recovery Problem consider that- the airline recovery problem, comparable to the planning issue, is a really big and complicated issue that is often divided into so many smaller, more tractable sequential phases.

(Sun, D., Sridhar, B., Grabbe 2012) proposed that a mesoscopic model of air traffic stream speak to handy elements and air traffic vulnerability. Based on this structure, an air course and system level framework for upgrading traffic stream is proposed by progressively booking flights. Next, a unique system is built up that embodies the topological structure of airspace and catches traffic stream elements. Second, to catch air traffic at total level [24], the proposed dynamic system of a Mesoscopic dynamic air traffic stream is created so as to consider elements and vulnerability in the wind current by methods for the continuum condition of liquid mechanics and spatial discretization of cell transport models. Thirdly, issues of enhancement of traffic stream on the course are settled with a double creation approach at both air course and system level. Another strategy is accordingly fabricated that fathoms increasingly commonsense models of the issue of advancing traffic stream end course. In view of this model, we take care of a stream enhancement issue by utilizing a double deterioration way to deal with execute asset limitations with negligible working expenses. The unwavering quality of the proposed model in the fruitful catch of the stream elements and the adequacy of the proposed advancement framework to limit start to finish delays by adjusting complex interest for traffic and airspace nonappearance show a contextual analysis of the start to finish airspace. 
P. Wei, Y. Cao, (2013) referenced that conceivable control exercises included ground and air delays (through changes in speed), redirection over an enormous system, and undoings. Based on the biggest issues unraveled to date with of air traffic stream the board, our hypothetical analyses show that the proposed arrangement is sufficiently proficient to be applied progressively. Notwithstanding having computational advantages, the effectively parallelizable nature of the strategy can possibly take into consideration decentralized, yet helpful, basic leadership among the different aircrafts. For flight-explicit working and postpone costs, the proposed arrangement utilizes segment age to survey ideal existence directions within the sight of confinements on system and flight access, just as limitations on air terminal and airspace capacity, airborne deferrals, land resources, reroutes and abrogations are known as potential activities of order. Within the sight of obscure capacity imperatives, which are spoken to by probabilistic situation trees, the technique is then extended to produce asset procedures. To take care of country scale issues from the United States, a versatile, parallel execution of our technique is utilized, showing that the arrangement is proficient enough for continuous usage.

Zhe Liang et al. (2013) investigated that most examinations in aircraft activities arranging research focus on the board issues that handle a customary flight plan that is viewed as the equivalent for every day of the week. The week after week plan is progressively reasonable and down to earth, the unpredictability of the advancement issues is drastically improved. In this record, we present another week by week revolution visit arrange portrayal for the week after week airplane upkeep directing issue (WAMRP). To evaluate the effectiveness of WRTNM, we utilized eight occurrences of genuine testing to test the WRTNM. The outcomes show that the proposed model is exceptionally minimal and versatile, with 5,700 flights and 330 airplane generally the size of the universes biggest. In a short time, the world's biggest armada of aircrafts will locate the best options in contrast to the calendar. We likewise propose an implanted structure to fix the WAMRP simultaneously as the week by week task of the armada. We assessed the implanted format on nine self-developed research cases. The experimental discoveries show that the incorporated model delivers close ideal booking choices at a sensible minute with 1,700 flights, 8 armadas of 110 air ship, and about a medium-sized aircraft.

Margellos, K., Lygeros, J.,(2013) recommended that we utilized the hypothesis of multi-state frameworks and a Markov-Chain model to build up a dependability examination. To begin with, we characterized the direction as a multi-state framework comprising of the most powerful parameters distinguished in the model of the 4D direction. Moreover, the causal examination empowered us to characterize different squares or study components. The paces of execution were characterized as: ideal, worthy and corrupted. For the worldwide model, we acquainted two arrangements of parameters with depict the worldwide change network: essential and non-crucial. The most prohibitive is the major square: on the off chance that it is debased, the way state is corrupted. The operational unwavering quality evaluation, accomplished utilizing Monte Carlo reenactment and arbitrary procedures (Markov) strategies, gives a structure to anticipating that it is so liable to enter a debased state for the direction. We utilize this examination to figure the level of change in the 4D direction and to propose restorative measures to address potential. This current paper's primary commitment is to give a strategy to surveying the heartiness of 4D directions and tending to their aggravation, which is a foundation of traffic synchronization and compromise.

Bertsimas D., Lulli G., Odoni A.R (2013) proposed that a situation based displaying technique to figure the issue and recommended an example based methodology based arrangement framework. For the most part, the subsequent example normal guess program prompts an enormous scale blended whole number program that can be settled for little size issues and just for a predetermined number of situations. A decentralized usage of the arrangement was proposed and examined so as to adapt to this issue. Then again, the exactness of the situations utilized is a key component in the achievement of this methodology. Our present work means to make situations enlivened by genuine circumstances. We are presently gathering certifiable information speaking to the NAS conditions. In this manner, streamlining programming for OPL-Cplex will be utilized to take care of the issue to improve for little measured situations. Future work will concentrate on investigating parallel execution and decay methods so as to additionally improve the time effectiveness of the proposed methodology. We display and talk about a situation based demonstrating way to deal with delineate atmosphere aggravation events in the NAS dependent on a stochastic time-space framework. Frequently proposed is a product model alongside an appropriated usage to defeat issues of adaptability.

Glover, C.N., Ball, M.O., (2013) recommended that we perceive the different viewpoints of postponement, in particular the interest side of airplane administrators and ANSPs and perspective of NM (supply side). We question the new First Come First Served principle to relieve ATFM slack, which, while reasonable, centers around postpones that are underneath AO's deferrals, for example proliferated delays. Furthermore, we address the issue of adherence to air terminal openings, considering the situation where an interest limit awkwardness at last course division influences tasks from air terminals that have just been blocked. We are proposing a two-level model that advantages from plan cradles, for example the capacity of flights to retain ATFM delay. The ATFM space portion framework limits the slack proliferated on resulting flights on the primary phase of the structure. We find such ATFM opening distribution on the subsequent level to improve adherence to air terminal spaces, protecting the ideal spread postpone minutes. Contrasted with the current ATFM space designation, the outcomes propose that some postpone cost reserve funds are additionally conceivable. For the most part these progressions come to the detriment of expanded postpone minutes for ATFM. To this end, work is as of now under approach to investigate potential upgrades in the costeffectiveness of the framework by following up on both the stock (versatile limit arrangement) and the interest side of the framework (item separation with inventive estimating), in a re-structured ATM esteem chain, trying to limit the hole between arranging skylines of AOs and ANSPs, which is accepted to be one of the key drivers of cost-wasteful aspects in the momentum framework's setting. 
Cong, W., Hu, M., (2014)implemented that so as to deductively and effectively create and actualize significant level hierarchical ideas and mechanization frameworks, an inside and out examination concerning the inborn traffichuman elements and highlights that isn't usually found in the writing is significant. To fill this hole, we propose to structure and break down air traffic frameworks a multilayer organize. A Route-based Airspace Network (RAN) and Flight Trajectory Network (FTN) embody fundamental physical and utilitarian highlights; an Integrated FlowDriven Network (IFDN) and an Interrelated ConflictCommunication Network (ICCN) are intended to speak to and meddle with air traffic stream transmissions from designer controller individually. To characterize the elements of air traffic and to clarify the fundamental instrument of "ATCOs-stream" collaborations, a hearty multi-layer organize is intended to consolidate and exhibit components, for example, airspace, air ship way, stream correspondences, potential clashes and the impedance exercises of ATCOs. An assortment of quantitative measurements of air traffic stream and human administrator (for example organize stream factors, mental intricacy of ATCOs, and tumult) were executed to additionally mirror the complexities of "machine-stream" communication at different granularities just as procedure nonlinearity. Checking the all inclusive statement of our outcomes and characterizing basic attributes that are answerable for subjectively extraordinary procedure practices is significant. Viable approach to supplement the presentation of ATCOrelated information in various situations is called human-in the-circle reproduction progressively. What's more, versatile meta-discernment techniques dependent on ICCN arrange examination uncover and decipher the elements and hidden instruments of "ATCOs-stream" connections. At last, at framework level, when traffic is changed to the semi-steady or blocked stage, tumult is recognized in the contention framework and human social framework. This investigation gives scientific apparatuses to comprehend complex humanstream communications in a wide scope of air traffic frameworks and supports future advancements and mechanization of savvy air traffic the executives frameworks.

StephaneBratu et al.( 2015) examined the carrier plans are dependent upon numerous reasons for disturbance, including team nonappearances, specialized disappointments, and poor climate. Aircrafts recoup when these unanticipated occasions occur by replanting their activities. In this paper, we present models and calculations for carrier recuperation plans that, by choosing which flight leg takeoffs to be deferred and which to drop, all the while set up recuperation plans for air ship, groups and travelers. We recreate a few days of activities utilizing the aircraft tasks control test system we assembled utilizing traveler and flight information from a significant US carrier. Our aircraft recovery models are tried utilizing the AOCC test system we have created, which resumes long stretches of flight leg choice exercises as recommended by one of our streamlining models. We reason that, while reestablishing aircraft asset timetables and decreasing carrier working costs, better operational decisions can be made progressively to lessen traveler deferrals and interruptions.

Daniela I. Borissova et al. (2016) analyzed the two strategies are identified - one is intended to evaluate a schedule that minimizes the total make time by solving a single optimization task and the other is focused on solving multiple optimization tasks in parallel. A combinatorial modeling of optimization is described for the goal and the appropriate algorithm is proposed. The enumerative combinatory approach described for optimal job shop scheduling is numerically checked for real laboratory scheduling problem. The paper's main contribution is the use of an enumerative combination method for deterministic open laboratory scheduling of unconstrained or semiconstrained storage data on multiple machines. The main goal is to decide with limited make time the processing schedule. It proposes an algorithm with branch for aggregate optimization and branch for parallel optimization.

Yicheng Zhang et al. (2016) examined that tends to a system wide booking issue forflight plans for end-course airspace to be created, balanced and advanced. The reason for booking is twofold: to help flight designs by giving dependable flight calendars to ideal stream imperatives; and to help end-course traffic control by guaranteeing protected and organized traffic direction. To begin with, we structure a calculation dependent on discrete flying machine stream assignments to create nonstop time flight plans. With respect to succession streamlining for blending traffic, this calculation is additionally improved. In a recreation domain, a flight planning framework was created. This paper delivers an endeavor to connect vital stream the board with operational traffic control, empowered by the current Collaborative Decision Making (CDM) procedure of ATFM where numerous levels are associated with key, prestrategic, and strategic flight choices.

Cheng Zhang et al. (2017) dissected the investigation concentrating on the issue of air ship recuperation (ARP). Interruptions consistently cause plan disappointments, all things considered, tasks and cause aircrafts to endure significant misfortunes. The principle goal of the issue of air ship recuperation is accordingly to diminish the general recuperation costs and to take care of the issue inside satisfactory runtime.For figures the ARP and utilize attainable flight line as the fundamental factors in the structure, an air ship recuperation framework (ARM) is proposed here. The attainable flight line (LOFs) is characterized as an arrangement of flights that a flying machine will fly inside a day. With the quantity of flights, the quantity of LOFs increments exponentially. Hence, to diminish the issue size, a two-organize heuristic is proposed. The calculation consolidates a heuristic scoring framework with an AARM to preselect LOFs. The technique is minded five states of genuine investigation. The computational outcomes show that the proposed model gives a decent issue plan and can be explained with the proposed system inside suitable runtime. The two-arrange heuristic essentially diminishes the quantity of LOFs after each stage lastly decreases the quantity of factors and requirements in the airplane recuperation model.

Gurtner G, Bongiorno C, Ducci M, et al (2017) recommended that general, diverse business way and freesteering systems are being assessed and we exhibit the model's capacities on an airspace that fuses these ideas. After numerical recreations with the model, we show that the controllers perform less activities in a free-steering situation, 
however the contentions are scattered over a bigger part of the airspace. This may possibly build the multifaceted nature of controllers ' strife identification and goals. As of now looking into the free-steering approaches visualized by SESAR, we have indicated that in this circumstance we can anticipate that controllers should lead fewer tasks yet to spread them over a bigger part of thairspace. By hypothesis, this would imply that the unpredictability controllers should manage an ascent. We have discovered a few measurements utilized in the writing to "measure" trouble in a specific airspace so as to explore this particular angle. Subsequent to picking four parts with very physical definitions, we checked whether they additionally have the ability to foresee the multifaceted nature variety for our calculation, for example the quantity of activities and the emotional multifaceted nature varieties for people, with straight relapses. Policymakers could utilize this positive capacity figure to test free steering in denser locales than it is now.It stays for a future work to investigate how the potential divisions of airspace into parts will influence direction the executives in the SESAR situation and whether this will bring about an expansion in trouble with regards to having various controllers.

Brudnicki, D.; Chastain, K.; Ethier, B. (2017) suggested thatto reduce the effects of obsolete simulators, it is important to review and analyze existing simulation learning methods to recognize inefficiencies, areas of development, and potential applications for new or modified simulation technologies. In order to accomplish this mission, existing literature following the current FAA Academy ATC training process was described and evaluated for possible areas of improvement in both training process and simulation software practice. Of these areas of improvement, decreasing instructors reliance during training were found to have the most benefits with the least cost and was recommended as the first area of improvement to be introduced in future training processes. The second and third suggestions, respectively, were accompanied by the use of web-based training tools and the upgrading of the functionality of existing simulation systems. The remaining two areas of change have not been deemed feasible at the moment; however, in future studies they are still proposed for further study. Recommendations for changes to the current training program will be made when established. The current training methods used at the FAA Academy and training centers are checked in literature. The Air Traffic Control (ATC) Training Program of the Federal Aviation Administration (FAA) to identify potential areas for improvement in the fields of simulator software and course content.

M. Sama, D. A. Ariano, and D. Pacciarelli, (2017) referenced that rerouting arranging model for $0-1$ cross breed dynamic course organize in a terminal region is actualized in this examination rather than the rerouting arranging model for tackling course arrange configuration issues in the fight procedure. A multi-target programming model is created for extra fuel utilization, postpone misfortune, time and course span, and the ideal plan is controlled by considering changes in flying machine speed and height in terminal airspace when the course is under convective climate. In the battle stage, it isn't important to consider the properties of the beginning and end purposes of the course in the issues of rerouting. Because of the disposition of the flight leg, the proposed model tends to the takeoff leg curve independently to address the single direction course organize issue in terminal regions. A promising line of research could focus on three-dimensional way decision. The ideal way choice methodology likewise takes the most limited arrangement of ways as the practical area under tempest climate. In this way, as indicated by the security and financial examination, the ideal arrangement is picked. Another future heading of research could be additionally investigated by considering the ground keeping takeoff methods and utilizing the $3 \mathrm{D}$ rainstorm climate information.

Bertsimas et al. (2018) dissected that proposing an Air Traffic Flow Management (ATFM) direction based framework to help SESAR and NextGen. Through this work, they fuse 4D direction based activities into ATFM through request to diminish greatest postpone expenses and increment airspace adaptability while accomplishing vitality effectiveness. Today, with the nonstop development of the air transport industry, ATFM assumes a significant job in decreasing air traffic delays. The first is that because of the part based airspace design, the model drops the requirements, with the goal that the airspace limit can be improved hypothetically while guaranteeing safe division. Each flight could be doled out a contention free 4D direction by acquainting aviation route setups with spread all stages from takeoff to landing. The subsequent component is that our ATFM model proposes a productive heuristic to deal with huge scale occurrences. The calculation could guarantee the nature of the arrangements through the underlying arrangements, and the calculation time increments straightly with the quantity of flights.

Chun-Hsien Chen et al. 2018 dissected that the present air traffic the executives frameworks can scarcely satisfy the need as of late with the constant development of the air transport industry. To improve the circumstance, a whole number enhancement model for Air Traffic Flow Management (ATFM) is proposed in this work which joins 4D direction based activities. Notwithstanding tending to the issues of flight-by-flight rerouting, land-holding slack, fuel utilization and flight cancelation, the framework additionally utilizes part less airspace designs. Dantzig-Wolfe deterioration and a heuristic technique were worked by section age to create 4D struggle free directions for each trip so as to settle the model effectively. The arrangement incorporates subtleties of all flying machine during 5-h period so that with the adjusted climate data, the format can be actualized just 4-5 times each day. The third is that the model in this work could address the fuel utilization issue and limit the absolute fuel utilization expenses of the whole framework to accomplish vitality proficiency, which is additionally SESAR's and Next Gen's objective.

(Wei Zhang et al. 2019) investigated the continued growth in the demand for air traffic, rising fuel prices and increasing concerns about the safety and environmental impact of air transport require the modernization of the United States Air Traffic Management (ATM) system. For many engineering fields, developing such a large-scale networked system involving complex interactions between automation and human operators poses new challenges. This paper discusses many important aspects from a process-level point of view of the future ATM system.In particular,

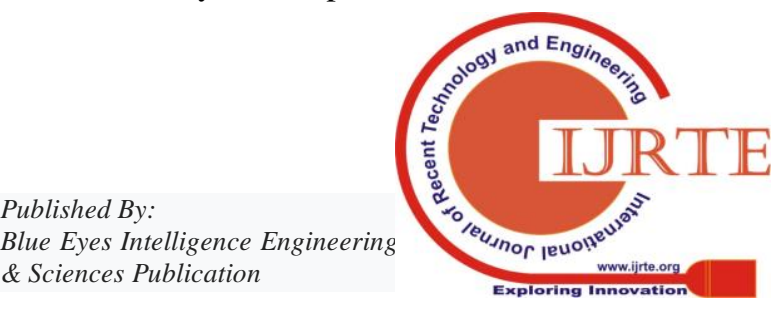


we are developing a decentralized hierarchical decision architecture that can design 4-D (space-time) path plans for a large number of flights while meeting the overall system's weather and capacity constraints. The current ATM system is both responsible for regulating safety and optimizing performance. This paper evaluates the hierarchical decision architecture for the future ATM system that distributes the task of optimization to users. With this structure, the ATM acts as a service provider that provides customers in regulatory data to optimize their own cost functions and participate in decision-making only in breach of regulatory laws.

Table I: Comparison of various techniques \& models proposed

\begin{tabular}{|c|c|c|c|}
\hline Research & $\begin{array}{l}\text { Model/ } \\
\text { method }\end{array}$ & Objective & $\begin{array}{c}\text { Result/ } \\
\text { finding/ } \\
\text { achievement }\end{array}$ \\
\hline $\begin{array}{c}\text { Amin et } \\
\text { al. } \\
{[31]}\end{array}$ & $\begin{array}{l}\text { Presented an } \\
\text { evolutionary } \\
\text { goal } \\
\text { programming } \\
\text { approach }\end{array}$ & $\begin{array}{l}\text { To create } \\
\text { scenarios } \\
\text { that satisfy } \\
\text { conditions } \\
\text { for four } \\
\text { conflict } \\
\text { sets to } \\
\text { evaluate } \\
\text { human } \\
\text { cognitive } \\
\text { load }\end{array}$ & $\begin{array}{c}\text { Three } \\
\text { modified } \\
\text { methods for } \\
\text { differential } \\
\text { development } \\
\text { outperform } \\
\text { standard } \\
\text { approaches }\end{array}$ \\
\hline $\begin{array}{c}\text { Yang et } \\
\text { al. } \\
{[32]}\end{array}$ & $\begin{array}{l}\text { Adopted a } \\
\text { stated } \\
\text { preference } \\
\text { approach, } \\
\text { designed } \\
\text { choice } \\
\text { scenarios and } \\
\text { accessed the } \\
\text { airport } \\
\text { operating } \\
\text { strategy } \\
\text { effects }\end{array}$ & $\begin{array}{l}\text { To model } \\
\text { the choice } \\
\text { behaviour } \\
\text { of flight } \\
\text { routes and } \\
\text { airports for } \\
\text { a direct } \\
\text { flight to } \\
\text { Shanghai } \\
\text { from } \\
\text { Taiwan }\end{array}$ & $\begin{array}{l}\text { Flying time } \\
\text { and air fare } \\
\text { significantly } \\
\text { affected the } \\
\text { passenger } \\
\text { route choice, } \\
\text { while access } \\
\text { cost and time } \\
\text { were } \\
\text { important } \\
\text { aspects for } \\
\text { airport } \\
\text { choices }\end{array}$ \\
\hline $\begin{array}{c}\text { Silva et } \\
\text { al. } \\
{[33]}\end{array}$ & $\begin{array}{l}\text { Utilized a } \\
\text { differentiated } \\
\text { duopoly } \\
\text { model }\end{array}$ & $\begin{array}{c}\text { To analyse } \\
\text { the airlines } \\
\text { behaviour } \\
\text { regarding } \\
\text { route } \\
\text { structure } \\
\text { choices }\end{array}$ & $\begin{array}{c}\text { An } \\
\text { instrument } \\
\text { aiming at } \\
\text { regulating } \\
\text { route } \\
\text { structure } \\
\text { choices might } \\
\text { be necessary }\end{array}$ \\
\hline $\begin{array}{c}\text { Wang } \\
\text { and Gong } \\
{[34]}\end{array}$ & $\begin{array}{c}\text { Proposed a } \\
\text { nonlinear } \\
\text { programming } \\
\text { mode }\end{array}$ & $\begin{array}{l}\text { To avoid } \\
\text { danger, } \\
\text { restricted } \\
\text { and } \\
\text { prohibited } \\
\text { areas }\end{array}$ & $\begin{array}{l}\text { Optimized } \\
\text { flight paths } \\
\text { avoiding the } \\
\text { areas }\end{array}$ \\
\hline
\end{tabular}

\begin{tabular}{|c|c|c|c|}
\hline $\begin{array}{c}\text { Schilke } \\
\text { and } \\
\text { Hecker } \\
{[35]}\end{array}$ & $\begin{array}{l}\text { Presented an } \\
\text { airplane- } \\
\text { based } \\
\text { dynamic } \\
\text { route } \\
\text { optimization } \\
\text { system }\end{array}$ & $\begin{array}{c}\text { To } \\
\text { optimize } \\
\text { the flight } \\
\text { path around } \\
\text { convective } \\
\text { weather }\end{array}$ & $\begin{array}{l}\text { Reducing a } \\
\text { fuel burn and } \\
\text { enabling } \\
\text { minimal } \\
\text { detergents }\end{array}$ \\
\hline $\begin{array}{c}\text { Yoon et } \\
\text { al. } \\
{[36]}\end{array}$ & $\begin{array}{l}\text { Presented a } \\
\text { geometric } \\
\text { model and } \\
\text { created an } \\
\text { optimal } \\
\text { combination } \\
\text { of ground } \\
\text { delay and } \\
\text { route choice }\end{array}$ & $\begin{array}{l}\text { To protect } \\
\text { against } \\
\text { weather } \\
\text { risk }\end{array}$ & $\begin{array}{l}\text { En-route } \\
\text { deceleration } \\
\text { occurred if } \\
\text { airspace was } \\
\text { allowed to } \\
\text { fly, and the } \\
\text { aircraft was } \\
\text { re-run. }\end{array}$ \\
\hline $\begin{array}{c}\text { Patron } \\
\text { and } \\
\text { Botez } \\
{[37]}\end{array}$ & $\begin{array}{l}\text { Proposed a } \\
\text { calculation } \\
\text { method using } \\
\text { GAs and } \\
\text { analysed } \\
\text { vertical and } \\
\text { lateral } \\
\text { navigation } \\
\text { profiles }\end{array}$ & $\begin{array}{c}\text { To } \\
\text { minimize } \\
\text { fuel } \\
\text { consumptio } \\
\mathrm{n}\end{array}$ & $\begin{array}{c}\text { Fuel } \\
\text { consumption } \\
\text { savings could } \\
\text { be obtained } \\
\text { up to } 5.6 \%\end{array}$ \\
\hline $\begin{array}{l}\text { Wei et al. } \\
\text { [38] }\end{array}$ & $\begin{array}{l}\text { Demonstrated } \\
\text { an optimal } \\
\text { metroplex } \\
\text { routing } \\
\text { paradigm }\end{array}$ & $\begin{array}{c}\text { For flexible } \\
\text { flights }\end{array}$ & $\begin{array}{l}\text { An integrated } \\
\text { flexible flight } \\
\text { operation } \\
\text { simulation } \\
\text { platform was } \\
\text { introduced }\end{array}$ \\
\hline $\begin{array}{c}\text { Kent and } \\
\text { Richards } \\
\text { [39] }\end{array}$ & $\begin{array}{l}\text { Presented a } \\
\text { geometric } \\
\text { method }\end{array}$ & $\begin{array}{l}\text { To find } \\
\text { optimum } \\
\text { routes for } \\
\text { commercial } \\
\text { formation } \\
\text { flight }\end{array}$ & $\begin{array}{l}\text { Provided } \\
\text { good } \\
\text { solutions to } \\
\text { allocate } \\
\text { formation } \\
\text { pairs and } \\
\text { significantly } \\
\text { reduced the } \\
\text { computing } \\
\text { time for all } \\
\text { possible wind } \\
\text { optimal } \\
\text { routes }\end{array}$ \\
\hline
\end{tabular}




\begin{tabular}{|c|c|c|c|}
\hline $\begin{array}{l}\text { Pyza and } \\
\text { Golda } \\
{[40]}\end{array}$ & $\begin{array}{l}\text { Presented } \\
\text { optimizing of } \\
\text { cargo } \\
\text { transportation } \\
\text { routes with } \\
\text { regional } \\
\text { airports and } \\
\text { the central } \\
\text { airport } \\
\text { included }\end{array}$ & $\begin{array}{l}\text { To obtain } \\
\text { the best } \\
\text { routes for } \\
\text { regional } \\
\text { airports } \\
\text { operations }\end{array}$ & $\begin{array}{c}\text { Routes } \\
\text { determination } \\
\text { was achieved } \\
\text { based on the } \\
\text { statistical } \\
\text { data } \\
\text { regarding the } \\
\text { transport } \\
\text { directions and } \\
\text { the cargo } \\
\text { managing } \\
\text { volume }\end{array}$ \\
\hline $\begin{array}{l}\text { Zuniga et } \\
\text { al. } \\
{[41]}\end{array}$ & $\begin{array}{l}\text { Presented a } \\
\text { discrete event } \\
\text { model and } \\
\text { conducted a } \\
\text { case study for } \\
20 \text { arrival } \\
\text { flights }\end{array}$ & $\begin{array}{l}\text { For conflict } \\
\text { detection } \\
\text { and } \\
\text { resolution }\end{array}$ & $\begin{array}{l}\text { The two } \\
\text { trajectories } \\
\text { proved to be } \\
\text { airworthy }\end{array}$ \\
\hline $\begin{array}{l}\text { Ruiz et } \\
\text { al. } \\
{[42]}\end{array}$ & $\begin{array}{l}\text { Presented a } \\
\text { 4D- } \\
\text { trajectories } \\
\text { based conflict } \\
\text { detection and } \\
\text { resolution } \\
\text { method }\end{array}$ & $\begin{array}{l}\text { Conflict } \\
\text { resolution i } \\
\text { n a } \\
\text { TMA }\end{array}$ & $\begin{array}{l}\text { Confirmed } \\
\text { the resulting } \\
\text { conflict-free } \\
\text { trajectory } \\
\text { using a } \\
\text { certified } \\
\text { flight } \\
\text { simulator and } \\
\text { real FMS } \\
\text { avionics }\end{array}$ \\
\hline $\begin{array}{l}\text { Taylor et } \\
\text { al. } \\
{[43]}\end{array}$ & $\begin{array}{c}\text { Proposed an } \\
\text { operational } \\
\text { ideas }\end{array}$ & $\begin{array}{c}\text { Improvinga } \\
\text { rrivals and } \\
\text { departures } \\
\text { high- } \\
\text { density- } \\
\text { area }\end{array}$ & $\begin{array}{c}\text { The concept u } \\
\text { tilizes } \\
\text { resources } \\
\text { more efficient } \\
\text { ly and reduce } \\
\text { s decision ma } \\
\text { kers workloa } \\
\text { d. }\end{array}$ \\
\hline
\end{tabular}

\subsection{Research Gap}

Previous research has demonstrated that the air traffic framework has the qualities of high operational multifaceted nature and misuse including numerous clients just as characteristic stochastic events in the activity of the system.

Air transport framework limit usage, for example enrooted airspace limit and air terminal runway limit, impacts ATFM quality. Pertinent ATFM contemplates have exhibited the estimation of the executives of air terminal ability to ATFM's performance.

Optimizing air traffic at TMA airport in terms of airport operating performance as well as planning airline distribution quality. Utilizing aircraft sequencing methods and propelled route advances, it was discovered plausible to augment the utilization of limited runway space at an air terminal.

$\square \quad$ With regard to the airlines ' operational efficiency on the apron, recent papers have shown that the quality of ground service differs among carriers and also influences airlines portability and productivity

\section{CONCLUSION}

Recently many Air Traffic Management projects included the utilization of long haul forecast of flying machine directions as a method for guaranteeing proficient and strife free flights from door to entryway. The Air Traffic Management System was created as a component of the Euro control PHARE program to give an airborne component to such tests. The potential proficiency of such approaches necessitates that it be conceivable to check directions against one another to recognize any contentions between them. A flying machine following an airplane direction issue and air ship recuperation issue would then be able to be guaranteed an issue free and unperturbed flight. Favored directions from a few airplane will unavoidably prompt clashes which must be settled by compelling at least one air ship to fly a non-ideal direction. This paper is worried about the airplane recuperation issue and flying machine direction issue to adjust an ideal direction as meager as conceivable with the end goal for it to have the option to meet limitations.

\section{FUTURE SCOPE}

The ATM industry (Air Traffic Controllers, Suppliers, Airplane manufacturers) today is a vast industrial and technological complex worldwide. It is well recognized that it takes a long time to introduce technological changes, particularly if systems need to be thoroughly tested for their security. In addition, the system requires synchronization between ground and airborne devices. Therefore, personnel, pilots as well as air traffic controllers, need to be qualified to use new technologies. The control of air traffic (ATM) is one of the most dynamic networks in the world. At the Florence Air Forums, FSR Transport often examines ATM issues, generally within the so-called Single European Sky (SES). After this debate, at the Madrid World ATM Congress, FSR Transport organized a global dialog session. Through their various ATM reform processes stakeholders from around the globe discussed their insights.

\section{REFERENCES}

1. Adacher, Ludovica \& Flamini, Marta \& Romano, Elpidio. (2017), Rerouting Algorithms Solving Air Traffic Congestion, AIP Conference Proceedings. 1836.

2. S. Harry, B. Richard, and L. Michael, "Next generation air transportation system (NGATS) air traffic management (ATM) airspace project," NGATS ATM-Airspace Project Reference Material (External Release), NASA, 2007.

3. Boeing: current market outlook. http://www.boeing.com/boeing/commercial/cmo/. Accessed 25 Nov 2013

4. Cond Rocha Mura M., Mller C., Control-based optimization approach for aircraft scheduling in a terminal area with alternative arrival routes, Transportation Research Part E: Logistics and Transportation Review, 73, 96-113, 2015. 
5. Liu, Yi, and Mark Hansen. "Ground Delay Program decision-making using multiple criteria: A single airport case." USA/Europe Air Traffic Management Research Development Seminar, Chicago, IL. 2013.

6. Zhang, Ming, Xianglu Kong, Kai Liu and Xiangyu Li. "A Novel Rerouting Planning Model for the Terminal Arrival Routes under the Influence of Convective Weather." (2018).

7. Ferduła, Paweł \& Skorupski, Jacek. (2018). The Influence of Errors in Visualization Systems on the Level of Safety Threat in Air Traffic. Journal of Advanced Transportation. 2018. 1-16

8. Bertsimas, Dimitris \& Lulli, Guglielmo \& Odoni, Amedeo. (2011). An Integer Optimization Approach to Large-Scale Air Traffic Flow Management. Operations Research. 59. 211-227.

9. Sridhar, Banavar \& Grabbe, Shon \& Mukherjee, Avijit. (2009). Modeling and Optimization in Traffic Flow Management. Proceedings of the IEEE. 96. 2060 - 2080.

10. Balakrishnan, H. and Chandran, B.G., 2014. Optimal large-scale air traffic flow management.

11. Gaétan Marceau Caron. Optimization and Uncertainty Handling in Air Traffic Management. Artificial Intelligence [cs.AI]. Paris-Sud XI, 2014.

12. Marcella Samà, Andrea D'Ariano, Dario Pacciarelli, Optimal Aircraft Traffic Flow Management at a Terminal Control Area during Disturbances, Procedia - Social and Behavioral Sciences, Volume 54, 2012, Pages 460-469, ISSN 1877-0428,

13. Chen, Jun \& Cao, Yi \& Sun, Dengfeng. (2017). Modeling, Optimization, and Operation of Large-Scale Air Traffic Flow Management on Spark. Journal of Aerospace Information Systems. 14. 1-13.

14. Qing Li, Yicheng Zhang, Rong Su, A Flow-based Flight Scheduler for En-route Air Traffic Management, IFAC-PapersOnLine, Volume 49, Issue 3, 2016, Pages 353-358,ISSN 2405-8963

15. Marceau, Gaétan \& Savéant, Pierre \& Schoenauer, Marc. (2013) Strategic Planning in Air Traffic Control as a Multi-objective Stochastic Optimization Problem.

16. Sailauov, Tolebi \& Zhong, Z.. (2019). An Optimization Approach towards Air Traffic Forecasting: A Case Study of Air Traffic in Changi Airport. Statistics, Optimization \& Information Computing. 7.

17. Diao, Xudong \& Chen, Chun-Hsien, 2018. "A sequence model for air traffic flow management rerouting problem," Transportation Research Part E: Logistics and Transportation Review, Elsevier, vol. 110(C), pages $15-30$

18. Hafidi, M., Benaddy, M., \& Krit, S. (2018). Review of optimization and automation of air traffic control systems. ICEMIS '18.

19. Zhong, Z. (2018), "Overview of recent developments in modelling and simulations for analyses of airspace structures and traffic flows," Advances in Mechanical Engineering.

20. Cheng-Lung Wu \& Robert E. Caves (2002) Research review of air traffic management, Transport Reviews, 22:1, 115-132.

21. Metz, Isabel. (2015), "Aircraft Performance for Open Air Traffic Simulations."

22. Salah-ddine, Krit \& Hafidi, Meryeme \& Benaddy, Mohamed. (2018), "Optimization and Automation of Air Traffic Control Systems: An Overview," 7.

23. Sun, D., Sridhar, B., Grabbe, S.R., Disaggregation Method for an Aggregate Traffic Flow Management Model, Journal of Guidance Control and Dynamics, 2012,33:666-676.

24. P. Wei, Y. Cao, and D. Sun, "Total unimodularity and decomposition method for large-scale air traffic cell transmission model," Transportation Research Part B, 53:1-16, 2013.

25. Zhe Liang, Zhang, H., Jin, J.P., Tang, L., et al. 2013, PlantTFDB 2.0: update and improvement of the comprehensive plant transcription factor database, Nucleic Acids Res., 39, D1114-7

26. Margellos, K., Lygeros, J., 2013, "Toward 4-D Trajectory Management in Air Traffic Control: A Study based on Monte Carlo Simulation and Reachability Analysis," IEEETrans. Control Syst. Technol. 21, 1820-1833.

27. Bertsimas D., Lulli G., Odoni A.R., “An Integer Optimization Approach to Large-Scale Air Traffic Flow Management", Operations Research, Vol. 59(1), pp. 211-227, 2013.

28. Glover, C.N., Ball, M.O., 2013. Stochastic optimization models for ground delay program planning with equity-efficiency tradeoffs. Transp. Res. Part C Emerg. Technol. 33, 196-202.

29. Cong, W., Hu, M., 2014. Chaotic characteristics analysis of air traffic system. Transactions of Nanjing University of Aeronautics and Astronautics, 31(6), 636-642

30. Sun, D., Sridhar, B., Grabbe, S.R., Disaggregation Method for an Aggregate Traffic Flow Management Model, Journal of Guidance Control and Dynamics, 2012,33:666-676.
31. Amin R, Tang J, Ellejmi M, et al. An evolutionary goal-programming approach towards scenario design for air-traffic human-performance experiments. In: Proceedings of the 2013 IEEE symposium on computational intelligence in vehicles and transportation systems (CIVTS), Singapore, 16-19 April 2013, pp.64-71. NewYork: IEEE

32. Yang $\mathrm{C}-\mathrm{W}, \mathrm{Lu} \mathrm{J}-\mathrm{L}$ and Hsu C-Y. Modeling joint airport and route choice behavior for international and metropolitan airports. $J$ Air Transp Manag 2014; 39: 89-95.

33. Silva HE, Verhoef ET and van den Berg VAC. Airline route structure competition and network policy. Transport Res B: Meth 2014; 67: 320-343.

34. Wang S-J and Gong Y-H. Research on air route network nodes optimization with avoiding the three areas. Safety Sci 2014; 66: 9-18.

35. Schilke $\mathrm{C}$ and Hecker P. Dynamic route optimization based on adverse weather data. In: Proceedings of the SESAR innovation days (SIDs

2014),https:/www.sesarju.eu/sites/default/files/documents/events/ SIDs_2014_Programme_Outline_v0_2.pdf

36. Yoon $\mathrm{Y}$, Hansen $\mathrm{M}$ and Ball MO. Optimal route decision with a geometric ground-airborne hybrid model under weather uncertainty. Transport Res E: Log 2012; 48: 34-49.

37. Patron RSF, Kessaci A, Botez RM, et al. Flight trajectories optimization under the influence of winds using genetic algorithms. In: Paper presented at the AIAA guidance, navigation, and control (GNC) conference, Boston, MA, 19-22 August 2013. Reston, VA: AIAA.

38. Wei P, Kim T, Han SY, et al. Optimal metroplex routing paradigm for flexible flights. J Guid Control Dynam 2013; 36: 1221-1224.

39. Kent TE and Richards AG. On optimal routing for commercial formation flight. In: Paper presented at the AIAA guidance, navigation, and control (GNC) conference, Boston, MA, 19-22 August 2013. Reston, VA: AIAA.

40. Pyza D and Golda P. Transport cargo handling shipments in air transport in the aspect of supply chains. In: Paper presented at the 201121 st international conference on systems engineering (ICSEng), Las Vegas, NV, 16-18 August 2011. New York: IEEE.

41. Zuniga CA, Piera MA, Ruiz S, et al. A CD\&CR causal model based on path shortening/path stretching techniques. Transport Res C: Emer 2013; 33: 238-256.

42. Ruiz S, Piera MA and Del Pozo I. A medium term conflict detection and resolution system for terminal maneuvering area based on spatial data structures and 4D trajectories. Transport Res C: Emer 2013; 26: 396-417.

43. Taylor C, Masek T and Bateman H. Framework for high-density-area departure and arrival traffic management. J Guid Control Dynam 2013; 36: 1134-1149 